\title{
Self-evaluation of lifestyle and assessment of health condition by clinical measurements - A call to the rural population
}

\author{
Pirjo Kaakinen*1, Uroš Železnik ${ }^{2}$, Helvi Kyngäs ${ }^{1,3}$, Danica Železnik ${ }^{4}$ \\ ${ }^{1}$ Research Unit of Nursing Science and Health Management, University of Oulu, Oulu, Finland \\ ${ }^{2}$ Quality of Life and Healthy Lifestyle Centre, University College of Health Sciences Slovenj Gradec, Slovenia \\ ${ }^{3}$ Northern Ostrobothnia Hospital District, Finland \\ ${ }^{4}$ University College of Health Sciences Slovenj Gradec, Slovenia
}

Received: February 14, 2018

DOI: $10.5430 /$ jnep.v8n11p30
Accepted: May 27, 2018

Online Published: June 19, 2018

\begin{abstract}
Background: Although many people know that a healthy lifestyle prevents chronic diseases and improves the quality of life, the best way to invite people from rural areas to take part in health check-ups is still unclear. The aim of this study was to examine the lifestyle and health condition of people from the Carinthia regions in Slovenia.

Methods: A cross-sectional study was conducted on 140 participants. Data were collected by questionnaire and clinical measurements and were analysed by descriptive statistical methods.

Results: Most of the participants were $\geq 60$ years old (62\%) and 61\% were women, $75 \%$ had a high BMI and 64\% had elevated blood pressure. The older participants ate breakfast more often than younger participants $(p=.010)$. There was a statistically significant connection between the number of daily hot meals and BMI $(p=.026)$ and blood pressure $(p=.049)$. Half of the participants $(51 \%)$ drank a litre of water per day as recommended. Hiking was the most popular form of physical activity.

Conclusions: The study findings recommended using a new way to call people in health check-ups in rural areas and provided information about the kind of lifestyle counselling rural people may need.
\end{abstract}

Key Words: Population, Health condition, Healthy lifestyle, Health education, Health check-ups

\section{INTRODUCTION}

New ways are needed to maintain and promote a healthy lifestyle to prevent functional disability and chronic disease. ${ }^{[1,2]}$ An unhealthy lifestyle caused by physical inactivity, obesity, poor quality diet, smoking and alcohol consumption is a preventable aspect of many diseases. ${ }^{[3,4]}$ The World Health Organisation (WHO) has defined ${ }^{[5]}$ that a healthy lifestyle includes physical, mental and social wellbeing, and it is more than just being without disease. This study focused on the physical wellbeing of Carinthia people by examining nutrition, physical activity and living habits.

Slovenia has developed a strategy to promote and maintain people's health. In Slovenia, as in other European countries, there are problems with people being overweight and obese, consuming high levels of alcohol or smoking a lot. ${ }^{[6]}$ Such lifestyle factors are major risk factors for cardiac disease and shorter life expectancy. Therefore, workshops have been introduced to promote a healthy lifestyle, such as weight loss

\footnotetext{
*Correspondence: Pirjo Kaakinen; Email: pirjo.kaakinen@oulu.fi; Address: Research Unit of Nursing Science and Health Management, University of Oulu, Oulu, Finland.
} 
groups for overweight people, health education centres carrying out activities that prevent harmful lifestyle habits and counselling of health and healthy lifestyles. It is known that people's experiences play a crucial role in relation to their attitude towards a healthy lifestyle. Despite much development work and strategy implementation in Slovenia, little is known about the lifestyle of people in rural areas concerning their diet, physical activity and health condition. However, a few changes in lifestyle can help people live more healthily.

A healthy lifestyle helps to prevent many chronic diseases and adds to the quality of life. ${ }^{[7,8]}$ Counselling on a healthy lifestyle mainly includes advice about nutrition, ${ }^{[1,3]}$ smoking habits and alcohol consumption, ${ }^{[4]}$ and physical activity. ${ }^{[9,10]}$ Nutritional counselling plays an important role in promoting a healthy lifestyle. ${ }^{[3]}$ Furthermore, patients' attitudes and behaviours regarding a healthy lifestyle influence the effectiveness of counselling advice. ${ }^{[11,12]}$

A healthy diet includes fruit, vegetables, low fat foods and fibre. ${ }^{[13]}$ According to Threapleton et al., ${ }^{[1]}$ fibre, fruit and vegetable intake lowers the risk of cardiovascular disease. A healthy lifestyle also means having regular eating times. ${ }^{[14]}$ An unhealthy diet causes patients to become overweight and leads to obesity. ${ }^{[13,15]}$ In adults, obesity is defined as having a BMI of $\geq 30 .{ }^{[16]}$ Physical activity brings benefits to people's health and contributes towards lower blood pressure, body fat, cholesterol and triglycerides. ${ }^{[9,17]}$ For adults, at least 150 minutes per week of moderate physical activity, 75 minutes per week of vigorous intensity physical activity or 30 minutes of moderate-intensity activity 5 times per week is recommended. ${ }^{[18,19]}$

Healthy lifestyles and health promotion have been studied in many countries in recent years. ${ }^{[1,20]}$ In rural areas, healthcare professionals play a key role in promoting a healthy lifestyle. However, there needs to be an easy way for people to assess their health condition together with healthcare staff. Slovenia has developed a strategy to promote and maintain health, as well as to promote a cultural vision of a healthy lifestyle and equity in health. However, new ways are needed to encourage people to take part in health condition check-ups. The aim of this study was to examine peoples' health condition and lifestyle in the Carinthia region of Slovenia. In addition, a key goal of the study was to assess how many people would respond to open invitations to participate in health check-ups.

\section{MethodS}

\subsection{Participants and design}

The Carinthia region is a small rural area in East Slovenia containing over 70,000 inhabitants. Most people in the Carinthia region work as farmers. In this study, people were invited twice, in May $2013(\mathrm{n}=63)$ and March $2014(\mathrm{n}=$ $77)$, to participate via radio broadcasts and newspaper adverts providing information about the study. There were no the eligibility criteria for participants. All participants were voluntary and participated in the study at the local University College of Health Sciences Slovenj Gradec (UCHS).

All participants were measured for weight and height, blood pressure, blood glucose and total cholesterol. The measurements were made by UCHS students under their teachers' guidance. At the end of measurement session, participants were asked to fill in a questionnaire. The questionnaire was based on Wallace et al. ${ }^{[21]}$ and Harrington's et al. ${ }^{[2]}$ selfrated health and lifestyle behaviour questionnaire. The questionnaire included some background questions, such as gender and age. Respondents were also asked to self-estimate daily food intake, water and other liquid consumption and daily alcohol consumption and smoking habits. In addition, they assessed their physical activity type and daily amount as part of a healthy lifestyle. The questionnaire utilised a five-point scale, ranging from " $5=5$ or more per day" to " $1=$ less than 5 per day" The institutional ethics committee from the University College of Health Sciences Slovenj Gradec (UCHS SG) approved the study. Informed written consent was obtained from all the participants. Participation was voluntary and annymity and confidentially assured during the study.

\subsection{Data analysis}

The data were analysed using the software package SPSS version 20.0. The background information and lifestyle variables were analysed by using descriptive statistics and missing values were not replaced. Differences between the background and lifestyle variables were studied using the chi-square test and $t$-test based on distribution. The results presented are statistically significant $(p<.05){ }^{[23]}$

\section{RESUlts}

\subsection{Health condition of Carinthia people}

Most participants were $\geq 60$ years old $(62 \%)$ and $61 \%$ were women $(p=.002)$ (see Table 1$)$. Three quarters of the participants $(75 \%)$ had BMI $\geq 25$. The majority of participants had elevated blood pressure $(\geq 140 / 90 \mathrm{mmHg})$. Almost all the participants $(86 \%)$ had normal blood glucose levels $(<5.6$ $\mathrm{mg} / \mathrm{dL}$ ) and $40 \%$ of the participants had normal cholesterol levels $(<5 \mathrm{mg} / \mathrm{dL})$ (see Table 1$)$.

\subsection{Self-assessed lifestyle of Carinthia people}

Almost half of the participants (49\%) ate three hot meals per day and most $(83 \%)$ ate breakfast in the morning (see Table 2 ). There were differences relating to hot meals per day and 
BMI $(p=.026)$, as well as blood pressure $(p=.049)$ : people who had less than three hot meals per day had elevated BMI and blood pressure. There were also differences relating to the participants' age and eating breakfast $(p=.010)$ : people under 60 years of age $(73 \%)$ did not eat breakfast as often as those who were 60 years or older $(90 \%)$.

Table 1. Background information of respondents

\begin{tabular}{llll}
\hline Characteristics $(\boldsymbol{n}=\mathbf{1 4 0})$ & $\boldsymbol{f}$ & $\mathbf{\%}$ & $\boldsymbol{p}$-value \\
\hline Gender & & & \\
$\quad$ Men & 54 & 39 & $.002^{*}$ \\
Female & 86 & 61 & \\
Age & & & \\
$\quad<60$ years & 58 & 41 & \\
$\geq 60$ years & 87 & 62 & \\
BMI & & & \\
$<25$ & 33 & 24 & \\
$\geq 25$ & 105 & 75 & \\
Health status & & & \\
$\quad$ Normal blood pressure $<140 / 90 \mathrm{mmHg}$ & 47 & 34 & \\
Normal blood glucose $<5.6 \mathrm{mg} / \mathrm{dL}$ & 120 & 86 & \\
$\quad$ Normal cholesterol $<5 \mathrm{mg} / \mathrm{dL}$ & 56 & 40 & \\
\hline
\end{tabular}

$* p<.05$

Table 1 shows that half of the participants (52\%) drank at least a litre of water per day. There were differences relating to participants age and water intake $(p=.035)$ : participants under 60 years of age (49\%) drank more water daily than those who were 60 years old or over $(58 \%)$. Coffee and tea were the most popular beverages (see Table 2). There were differences in relation to the participants' age and use of carbonated beverages $(p=.009)$ : people aged sixty years and older $(7 \%)$ drank less carbonated beverages than participants under 60 years old (23\%) (see Table 2). There were also differences in relation to the participants' smoking and BMI $(p=.018)$. In addition, the participants' blood pressure $(p$ $=.043)$ and blood glucose $(p=.030)$ were related to their alcohol consumption. There were differences in relation to the participants' age and smoking habits $(p=.001)$.

There were differences in relation to blood glucose levels and consumption of vegetables $(p=.005)$, meat $(p=.004)$ and fruit ( $p=.007$ ) (see Table 3 ). Of the people with normal blood glucose levels, $75 \%$ ate vegetables, whereas only $40 \%$ of people with elevated blood glucose levels ate vegetables. Of the participants with normal blood glucose levels, $63 \%$ ate meat, whereas of the participants with elevated levels $100 \%$ stated that they ate meat. Of the people with normal blood glucose levels, $63 \%$ ate fruit, whereas of the participants with elevated levels, only $27 \%$ ate fruit. In addition, there were differences in relation to pasta eating and cholesterol $(p=.046)$ : of the participants who had a normal cholesterol level, $32 \%$ ate pasta, whereas of the participants with elevated cholesterol, only $17 \%$ ate pasta. Hiking was the most popular form of physical exercise (see Table 2). The mean time for daily recreation varied from 60 to $120 \mathrm{~min}$.

Table 2. Respondents' lifestyle habits

\begin{tabular}{|c|c|c|c|}
\hline & $f$ & $\%$ & $p$-value \\
\hline \multicolumn{4}{|l|}{ Eating habits $(n=132)$} \\
\hline \multicolumn{4}{|l|}{ Hot meals/day } \\
\hline 2 & 11 & 8 & \multirow{5}{*}{$p=.026^{\ddagger} ; p=.049^{\ddagger \ddagger}$} \\
\hline 3 & 65 & 49 & \\
\hline 4 & 40 & 30 & \\
\hline 5 & 15 & 11 & \\
\hline 6 & 1 & 0.8 & \\
\hline \multicolumn{4}{|l|}{ Breakfast } \\
\hline Yes & 110 & 83 & \multirow[t]{2}{*}{$p=.010^{* *}$} \\
\hline No & 23 & 17 & \\
\hline \multicolumn{4}{|c|}{ Amount of liquids $(n=136)$} \\
\hline Water & $N$ & $\%$ & \multirow{5}{*}{$p=.035^{* *}$} \\
\hline Up to 0.51 & 11 & 8 & \\
\hline Up to 11 & 69 & 52 & \\
\hline Up to 21 & 50 & 38 & \\
\hline More than 21 & 6 & 5 & \\
\hline \multicolumn{4}{|l|}{ Other liquids } \\
\hline Coffee & 110 & 83 & \multirow{6}{*}{$p=.009 * *$} \\
\hline Tea & 105 & 80 & \\
\hline Flavoured water & 25 & 19 & \\
\hline Juice & 44 & 33 & \\
\hline Fruit drink & 34 & 26 & \\
\hline Carbonated beverages & 17 & 13 & \\
\hline \multicolumn{4}{|l|}{ Bad habits } \\
\hline Smoking & 13 & 10 & $p=.018^{\ddagger} ; p=.001 * *$ \\
\hline Alcohol consumption & 49 & 37 & $p=.043^{\neq \ddagger} ; p=.030^{* * *}$ \\
\hline \multicolumn{4}{|c|}{ Form of recreation $(n=140)$} \\
\hline Hiking & 139 & 99 & \\
\hline Exercise & 38 & 27 & \\
\hline Cycling & 29 & 21 & \\
\hline \multicolumn{4}{|c|}{ Daily recreation/min. (mean) 65-77 } \\
\hline
\end{tabular}

Table 3. Consumption of common daily foodstuff items (n $=140$ )

\begin{tabular}{llll}
\hline Foodstuff & $\boldsymbol{n}$ & $\mathbf{\%}$ & $\boldsymbol{p}$ \\
\hline Meat & 93 & 66 & $.004^{*}$ \\
Vegetables & 100 & 71 & $.005^{*}$ \\
Fruit & 82 & 59 & $.007^{*}$ \\
Bread & 48 & 34 & \\
Potatoes & 35 & 25 & \\
Pasta & 32 & 23 & $.046^{* *}$ \\
\hline
\end{tabular}

*blood glucose, **cholesterol 


\section{Discussion AND CONCLUSION}

The results of this study show that it is possible to invite participants by open invitation and use nursing students during health check-ups, providing the students with an opportunity to practice their clinical skills and active interaction in a real situation. The results demonstrated that rural people were interested in having their health condition measured. In the future, inviting people to this kind of health check-up may provide an excellent opportunity for offering counselling on health promotion. Thomas et al. ${ }^{[8]}$ argued that health promotion is not optimal in primary care and, in Slovenia, there is currently a lack of resources for health promotion.

According to Befort et al., ${ }^{[24]}$ people who live in rural areas typically have a higher BMI than those living in cities. Similar results were obtained in this study. Therefore, people in rural areas would clearly benefit from lifestyle modification. One way to increase awareness of eating habits is to keep a diary of food intake. Inability to recognise the need for lifestyle modification may require counselling, which could be ineffective if not motivated towards lifestyle changes Although lifestyle changes can be made, the key question is how permanent those changes are? According to Khare et al., ${ }^{[25]}$ only vegetable consumption and physical activity were sustained for over a year in participants. Most people need support to receive benefits from lifestyle changes. ${ }^{[26]}$ Such support is not always readily available in rural areas. ${ }^{[27]}$ According to previous studies, healthy lifestyle changes have a positive impact on the quality of life as well as mental health. ${ }^{[28]}$

One reason for the good physical activity of the participants from in the Carinthia region is it contains a good hiking mountain. However, lack of public transportation and living in rural areas creates barriers to having hobbies and engaging in different kinds of physical activity, such as swimming and group exercise. Although there were good results in this study in some areas, there is still a need to find new ways to motivate people in lifestyle changes and adopt different ways for implementing health counselling, such as via the internet.

Limitations of the results include the regional aspect and number of participants. To maximise participation, we used the local newspaper and radio to invite people to take part in a free health check-up. In the future, it may be important to consider the season when health check-ups are offered because most people in the Carinthia region are farmers, so Spring is a busy time for them. The data were gathered using a self-reported questionnaire on lifestyle, which may have affected how the participants answered the questionnaire. There may have also been a bias of memory because people retrospectively self-estimated their daily food consumption and physical activity. The environmental conditions and distance of the University College may have affected whether potential participants were able to attend the health check-up. In conclusion, introduction of free health condition checkups could be an effective way to motivate people's lifestyle changes and check their health condition, especially in older people.

\section{ACKNOWLEDGEMENTS}

We would like to thank all participants from Carinthia region.

\section{CONFlicts of InTEREST Disclosure}

The authors declare that there is no conflict of interest.

\section{REFERENCES}

[1] Threapleton D, Greenwood D, Evans C, et al. Dietary fibre intake and risk of cardiovascular disease: systematic review and meta-analysis. BMJ. 2013; 347(19): 1-12.

[2] World Health Organisation, WHO. Health aging. 2015. Available from: http://www.euro.who.int/en/health-topics/Life -stages/healthy-ageing

[3] Dehghan M, Mente A, Teo K, et al. Relationship between healthy diet and risk of cardiovascular disease among patients on drug therapies for secondary prevention: a prospective cohort study of 31,546 highrisk individuals from 40 countries. Circulation. 2012; 126(23): 27052712. PMid:23212996 https : //doi .org/10.1161/CIRCULATIO NAHA . 112.103234

[4] Spring B, Moller A, Colangelo L, et al. Healthy lifestyle change and subclinical atherosclerosis in young adults: Coronary Artery Risk Development in Young Adults (CARDIA) study. Circulation. 2014;
130(1): 10-17. PMid:24982115 https://doi.org/10.1161/CI RCULATIONAHA. 113.005445

[5] World Health Organisation. Healthy living: what is a healthy lifestyle? 1999. Available from: http://apps.who.int/iris/ handle/10665/108180

[6] The European Health Report. Targets and beyond - Reaching new frontiers in evidence. Highlights. 2015. Available from: http://www.euro.who.int/__data/assets/pdf_fil e/0008/284750/EHR_High_EN_WEB.pdf?ua=1

[7] Kivelä K, Elo S, Kyngäs H, et al. The effects of health coaching on adult patients with chronic diseases: a systematic review. Patient Education and Counseling. 2014; 97(2): 147-157. PMid:25127667 https ://doi.org/10.1016/j.pec. 2014.07.026

[8] Thomas K, Bendtsen P, Jrevers B. Implementation of healthy lifestyle promotion in primary care: patients as coproducers. Patient Education and Counseling. 2014; 97(2): 283-290. PMid:25154336 https://doi.org/10.1016/j.pec.2014.07.033 
[9] Yates T, Haffner SM, Schulte PJ, et al. Association between change in daily ambulatory activity and cardiovascular events in people with impaired glucose tolerance (NAVIGATOR trial): a cohort analysis. Lancet. 2014; 383(9922): 1059-1066. https ://doi .org/10.101 6/S0140-6736(13)62061-9

[10] Lee W, Choi KC, Yum R, et al. Effectiveness of motivational interviewing on lifestyle modification and health outcomes of clients at risk or diagnosed with cardiovascular diseases: a systematic review. International Journal of Nursing Studies. 2016; 53: 331-41. PMid:26493130 https ://doi.org/10.1016/j.ijnurstu. 201 5.09 .010

[11] Kääriäinen M, Kyngäs H. The quality of patient education evaluated by health personnel. Scandinavian Journal of Caring Science. 2010; 24(3): 490-498. PMid:20210901

[12] Kaakinen P, Kääriäinen M, Kyngäs H. The chronically ill patients' quality of counseling in the hospital. Journal of Nursing Education and Practice. 2012; 2(4): 114-123. https://doi.org/10.5430/ jnep.v2n4p114

[13] Tarro L, Llauradó E, Moriña D, et al. Follow-up of a healthy lifestyle education program (the Educació en Alimentació Study): 2 years after cessation of intervention. Journal of Adolescent Health. 2014; 55(6): 782-789. PMid:25193385 https://doi.org/10.1016/j. jadohealth.2014.06.020

[14] Fulkerson JA, Larson N, Horning M, et al. A review of associations between family or shared meal frequency and dietary and weight status outcomes across the lifespan. Journal of Nutrition and Education Behaviour. 2014; 46(1): 2-19. PMid:24054888 https : //doi.org/10.1016/j·jneb.2013.07.012

[15] Nordestgaard B, Palmer T, Benn M, et al. The effect of elevated body mass index on ischemic heart disease risk: causal estimates from a Mendelian randomisation approach. PLoS Medicine. 2012; 9(5): e1001212.

[16] World Health Organization, WHO. Increasing fruit and vegetable consumption to reduce the risk of noncommunicable diseases. eLibrary of Evidence for Nutrition Actions (eLENA). 2015. Available from: http://www.who.int/elena/titles/fruit_veg etables_ncds/en/

[17] Cornelissen VA, Smart NA. Exercise training for blood pressure: a systematic review and meta-analysis. Journal of the American Heart Association. 2013; 2(1): e004473. PMid:23525435

[18] Chudyk A, Petrella RJ. Effects of exercise on cardiovascular risk factors in type 2 diabetes: a meta-analysis. Diabetes Care. 2011;
34(5): 1228-1237. PMid:21525503 https ://doi.org/10.2337/ dc10-1881

[19] World Health Organization, WHO. Physical activity, fact sheet $\mathrm{N}^{\circ} 385$. 2015. Available from: http://www. who.int/mediacen tre/factsheets/fs385/en/

[20] Železnik U, Gmajner S, Železnik D. The effect of demographic factors on self-image and self-esteem of over nourished participants of programmed health education. Wulfenia. 2015; 22(5): 175-187.

[21] Wallance PG, Brennan PJ, Haines AP. Are general practitioners doing enough to promote healthy lifestyle? Findings of the Medical Research Council's general practice research framework study on lifestyle and health. British Medical Journal (Clinical Research Ed). 1987; 294(6577): 940-942. https : //doi .org/10.1136/bmj . 29 4.6577 .940

[22] Harrington J, Perry IJ, Lutomski J, et al. Living longer and feeling better healthy lifestyle, self-rated health, obesity and depression in Ireland. European Journal of Public Health. 2010; 20(1): 91-95. PMid:19587230 https ://doi.org/10.1093/eurpub/ckp102

[23] Polit D, Beck C. Nursing Research. International Edition. 9th revised international ed. Lippincott Williams and Wilkins. 2011.

[24] Befort C, Nazir N, Perri M. Prevalence of obesity among adults from rural and urban areas of the United States: findings From NHANES (2005-2008). Journal of Rural Health. 2012; 28(4): 392 397. PMid:23083085 https://doi .org/10.1111/j.1748-036 1.2012.00411.x

[25] Khare M, Koch A, Zimmermann K, et al. Heart smart for women: a community-based lifestyle change intervention to reduce cardiovascular risk in rural women. Journal of Rural Health. 2014; 30(4): 359368. PMid:24576081 https://doi.org/10.1111/jrh.12066

[26] Petosa R, Smith L. Peer mentoring for health behavior change: a systematic review. American Journal of Health Education. 2014; 45(6): 351-357. https : //doi .org/10.1080/19325037.2014.945670

[27] Krummel D, Humphries D, Tessaro I. Focus groups on cardiovascular health in rural women: implications for practice. Journal of Nutrition and Education Behaviour. 2002; 34(1): 38-46. https : //doi .org/10.1016/S1499-4046(06)60223-6

[28] Groh C, Urbacic J. The impact of a lifestyle change program on the mental health of obese under-served African American women. Archives of Psychiatric Nursing. 2015; 29(2): 76-82. PMid:25858198 https ://doi.org/10.1016/j.apnu.2014.11.001 